Ovarian ablation is accepted as of value in certain age groups.

The potential role of chemotherapy in operable breast cancer is discussed.

I have to thank my colleagues in the Royal Infirmary, Aberdeen, for permission to use their case records in the preparation of this paper, and especially Dr. Roy Weir for his guidance and comment on the statistics.

\section{REFERENCES}

Bloom, H. J. G. (1950). Brit. F. Cancer, 4, 259, 347. 213.
Hodnett, E. M. (1963). Cancer Chemother. Rep., No. 32, p. 55.

Horwitz, H. (1960). Brit. 7. Radiol., 33, 659.

International Union Against Cancer (1959). Ibid. 32, 824

Internat. Cancer, 7, 37

McWhirter, R. (1954). Brit. F. Radiol., 27, 649.

McWhirter, R. (1954). Brit.

$$
\text { (1955). Ibid., 28, 128. (Lond.), 8, } 220 .
$$

Moore, G. E., Sandberg, A. A., and Watne, A. L. (1960). F. Amer. med. Ass., 172, 1729.

Park, W. W., and Lees, J. C. (1951). Surg. Gynec. Obstet., 93, 129. Paterson, R., and Russell, M. H. (1959). F. Fac. Radiol. (Lond.), $10,175$. - (1959). Ibid., 10, 130

Philip, J. F. (1949). Malignant Disease. Aberdeen.

Riddell, V. H. (1950). Brit. 7. Cancer, 4, 289.

Smithers, D. W (1952) F. Fac. Radiol. (Lond.), 4, 89.

Watson, T. (1959). Lancet, 1, 1191.

\title{
Selective Lymphopenia in Man after Intralymphatic Injection of Radioactive ${ }^{131}$ I Lipiodol
}

\author{
J. M. EDWARDS,* M.S., F.R.C.S. ; R. W. LLOYD-DAVIES, † F.R.C.S. ; J. B. KINMONTH, $\ddagger$ M.S., F.R.C.S.
}

Brit. med.F., 1967, 1, 331-335

There are several problems associated with the homotransplantation of tissue in man, not least of which is the homograft rejection mechanism. Certainly with kidney transplantation the technical problems of implantation appear subservient to those concerned with the rejection phenomenon.

The role of lymphocytes in this immune response is not fully understood, but there is ample evidence of their special importance (Woodruff, 1960). Loss of lymphocytes from the thoracic duct in rats resulted in severe depression or abolition of the primary immune response (McGregor and Gowans, 1963), and multiple methods of producing lymphocyte reduction have been used as a means of prolonging homograft survival in both experimental animals and man.

Over the past four years we have been particularly interested in the treatment of melanoma with endolymphatic ${ }^{131} \mathrm{I}$ Lipiodol. Before this period lymph-node metastases from melanoma had been treated with endolymphatic ${ }^{198} \mathrm{Au}$ (Jantet et al., 1964).

Complete records have been made in a series of 50 patients who received endolymphatic ${ }^{131}$ I therapy for melanoma. These investigations included preoperative and postoperative leucocyte estimations. It was noted in our early investigations that the endolymphatic therapy in the range of dosages used did not depress the total leucocyte count markedly, though this did occur in the occasional patient. However, of more significance was the feature that in several patients a relative and absolute lymphopenia occurred.

This paper is concerned with a detailed analysis of these patients, with particular reference to the achievement of a relative and absolute lymphocyte depression after endolymphatic therapy.

\section{Treatment Policy for Melanoma}

Our therapeutic approach to the patient with malignant melanoma is to follow the initial wide excision of the primary lesion with endolymphatic therapy via the lymphatics draining the site of excision. The endolymphatic treatment is usually given three weeks after the time of excision, though when the

* Senior Surgical Registrar.

$\dagger$ Research Fellow.

$\ddagger$ Professor of Surgery

Department of Surgery, St. Thomas's Hospital Medical School, London. diagnosis is assured synchronous treatment is occasionally given.

Should the lymph nodes be clinically and radiologically negative then this plan of action is usually regarded as sufficient and the patient is subsequently followed carefully in the outpatient department. In some patients node dissections have been made at varying intervals after endolymphatic treatment. Microscopical examination often reveals total destruction of lymph nodes in this group (see Fig. 1).

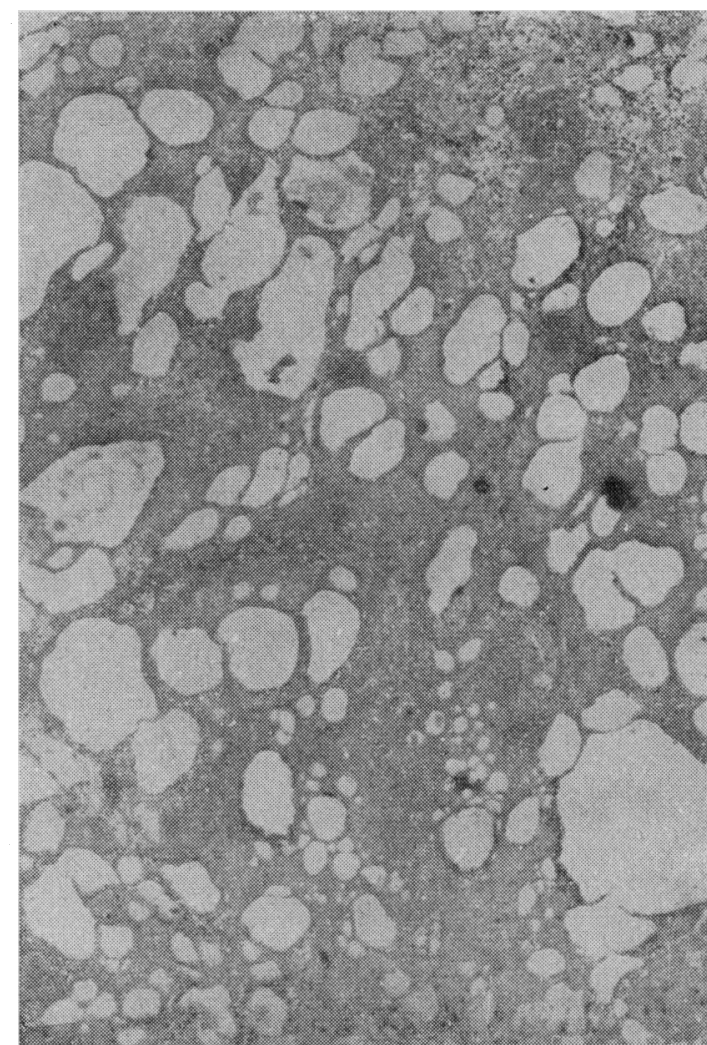

FIG. 1.-Total destruction of lymph node. ${ }^{131} 1$ Lipiodol represented by vacuolated spaces. Married woman. Melanoma of leg treated with endolymphatic ${ }^{131}$ I Lipiodol after wide excision of primary tumour. Lymph nodes in inguinal region removed six weeks later. 
However, regional nodes adjudged clinically and radiologically positive with respect to metastases always require further treatment (see Fig. 2). This is due to the short penetration of the $\beta$-particle of ${ }^{131} \mathrm{I}$ in tissue (see Table I). Consequently the large metastases would not be destroyed completely. A lymphnode block dissection is performed when the activity has subsided to a "safe level," after a period of about four to six weeks following the endolymphatic infusion. The combination of the two procedures in the patient with heavily involved

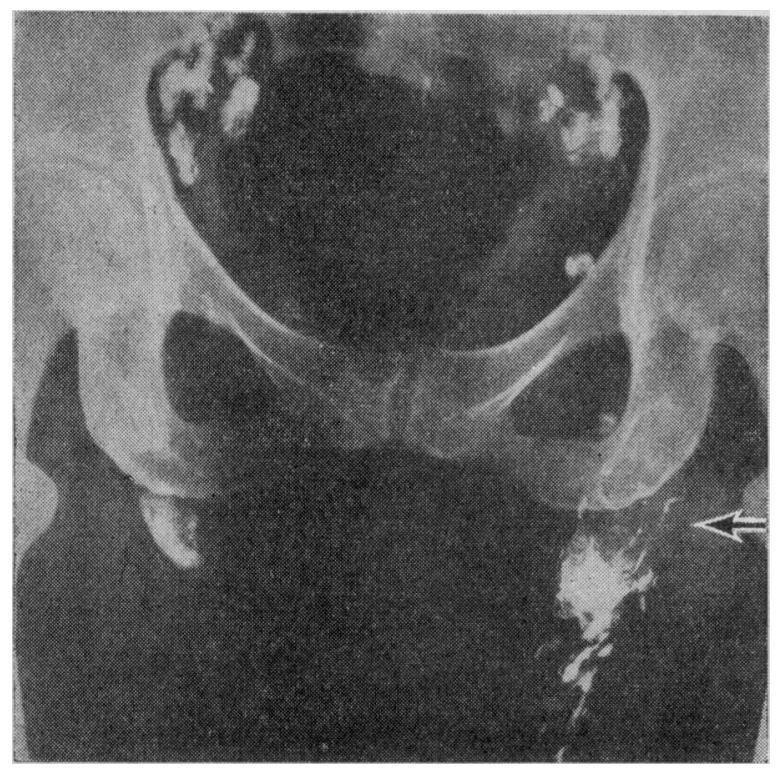

FIG. 2.- - spinster. Melanoma of lett leg with enlarged gland in left inguinal area. Arrow indicates heavily involved node. Clinical and radiological stage 2. This degree of involvement of lymph nodes by metastatic tumour in evitably means combination of ${ }^{131}$ I Lipiodol with block dissection. On right side non-radioactive Lipiodol was injected and the nodes shown are normal.

lymph nodes may offer certain advantages over the standard approaches: (1) more extensive treatment of lymph tissue is effected-lymph nodes beyond the normal limits of a node dissection and which may contain microscopic-size metastases are irradiated ; (2) any lymphoid tissue inadvertently left behind after the lymph-gland dissection would bc less likely to contain viable tumour cells; and (3) spillage of viable tumour cells during the gland dissection, leading to implantation, would be less likely to occur after previous irradiation.

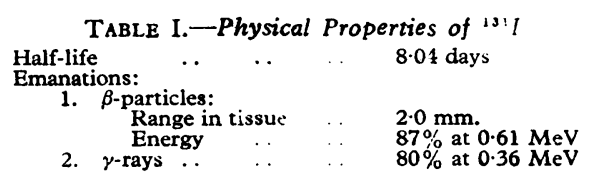

The patient with the clinically negative regional lymph nodes naturally offers the greatest hope of survival, but the results in both groups to date offer encouragement. It should be re-emphasized that though lymph nodes may be indicated to be non-involved on clinical examination careful histological examination has shown involvement by microscopic-size metastases. In one large group reported by Fortner, Booher, and Pack (1963) the regional lymph nodes, though clinically negative when treated by prophylactic block dissection, were found to be involved with microscopic-size metastases in $38 \%$ of cases.

After endolymphatic infusion, routine procedures include serial lymphadenogram studies, total body scanning, and serial blood estimations, both during inpatient stay and in the followup clinic. Total body scanning in these patients shows the highest counts over the regional lymph nodes, with lesser counts over the lung fields.

\section{Range of Dosage}

The dosage scheme for a melanoma of the lower limb when the ilioinguinal and para-aortic glands are irradiated is $40-45$ $\mathrm{mCi}$ in 4-4.5 ml. Lipiodol. Brachial infusion to cover the axillary nodes usually entails dosages of $30-35 \mathrm{mCi}^{131} \mathrm{I}$ in 2-2.5 ml. Lipiodol. Bilateral brachial and four-quadrant infusions have been given to some patients with melanoma of trunk or back, with corresponding dosages to each group of nodes.

The dosages quoted are those given at the present time. At the beginning of the work rather lower dosages were given. The radiation dose in rads to the lymph nodes has been estimated by direct measurement up to 100,000 rads. This calculation has been made by using the formula of Hine and Brownell (1956).

\section{Melanoma Series of Patients}

The fifty patients reviewed are subdivided into various groups, as indicated in Tables II and III. The effects of the endolymphatic radiation on the white blood counts are outlined in Table II. TABLE II.-Effects of Endolymphatic Therapy on Whize Blood-cell
Counts, According to Regions Treated, in 50 Patients with Melanoma. Details of Dosages are Given in the Text

\begin{tabular}{|c|c|c|c|c|c|}
\hline \multirow{2}{*}{$\begin{array}{c}\text { Site of } \\
\text { Intralymphatic } \\
\text { Injection }\end{array}$} & \multirow[t]{2}{*}{$\begin{array}{l}\text { No. of } \\
\text { Cases }\end{array}$} & \multicolumn{2}{|c|}{$\begin{array}{l}\text { Absolute } \\
\text { Lymphocyte } \\
\text { Depression }\end{array}$} & \multirow{2}{*}{$\begin{array}{c}\text { Late } \\
\text { Total } \\
\text { Leucocyte } \\
\text { Depres- } \\
\text { sion }\end{array}$} & \multirow{2}{*}{$\begin{array}{l}\text { Lympho- } \\
\text { penia } \\
\text { Prolonged } \\
\text { More than } \\
\text { One Month }\end{array}$} \\
\hline & & No. & $\%$ & & \\
\hline $\begin{array}{l}\text { Lower-limb infusion one side } \\
\text { Upper-limb "\# biläteral } \\
\text { Four quadrant infusion }\end{array}$ & $\begin{array}{r}35 \\
11 \\
3 \\
1 \\
\end{array}$ & $\begin{array}{r}23 \\
2 \\
1 \\
1 \\
\end{array}$ & $\begin{array}{r}65 \cdot 7 \\
18 \cdot 0 \\
33 \cdot 3 \\
100 \\
\end{array}$ & $\begin{array}{l}6 \\
0 \\
0 \\
1 \\
\end{array}$ & $\begin{array}{l}8 \\
0 \\
0 \\
1\end{array}$ \\
\hline Total & 50 & 27 & & 7 & 9 \\
\hline
\end{tabular}

$$
\begin{gathered}
\text { TABLE III.-Anatomic Sites of Primary } \\
\begin{array}{c}
\text { Melanoma } \\
\text { No. of cases treated }(36 \text { female, } 14 \text { male })
\end{array} \\
\begin{array}{c}
\text { Female/male ratio }=2 \cdot 5: 1 \\
\text { Site of Primary Lesion }
\end{array}
\end{gathered}
$$

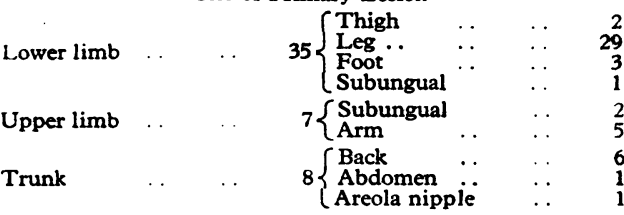

These groups form naturally according to whether the primary melanoma was situated on the lower limbs, upper limbs, back, or trunk. Relatively few melanomas of the face have been treated under our care; those treated with cervical intralymphatic injections are not included in this review. The site of origin of the primary lesions is indicated in a summarized form as Table III (melanoma series).

It was noted on examination of routine leucocyte counts that in some patients an absolute lymphopenia occurred in the early postoperative period, usually unassociated in this phase with any depression of the total leucocyte counts. The only other change noted was the occasional elevated erythrocyte rate, and this appeared to be directly related to the level of spillover of radioactivity to the lung fields. When this was appreciable, as indicated by the external scanning findings, then the E.S.R. was usually raised from the normal preoperative value. On examination of repeated leucocyte estimations in the later postoperative period and also from the outpatient clinic a mild late depression of the total W.B.C. was occasionally noted. This never reached levels which would cause anxiety and was not associated with a marked thrombocytopenia.

On examination of the individual groups it was further noted, as seen in Table II, that the patie 'rts receiving endolymphatic ${ }^{131}$ I Lipiodol treatment to the ilioinguinal and para-aortic 
regions were those which showed the most frequent and prolonged depression of both lymphocyte counts and leucocyte estimations. An illustrative example is shown in Fig. 3. In this patient with normal preoperative W.B.C. estimations the endolymphatic infusion after excision of the primary melanoma of the calf was followed by an absolute lymphopenia to the order of 500 cells per cu. mm. at first. It persisted for two months, and later was associated with a mild depression of the total leucocyte value. This was illustrative of many cases treated with lower limb infusions, though few of the patients showed depression beyond one month's duration.

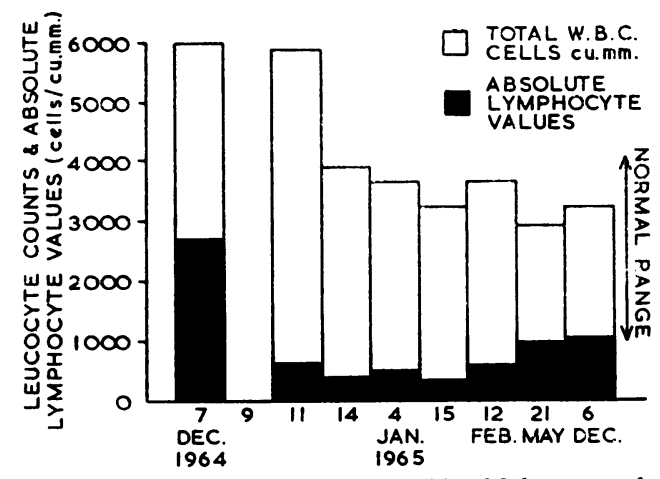

FIG. 3.-Married woman aged 55. Melanoma of leg. Infusion of $5 \mathrm{ml}$. ${ }^{131} \mathrm{I}$ Lipiodol containing $35 \mathrm{mCi}{ }^{131} \mathrm{I}$ on 9 December 1964. Serial total
leucocyte and lymphocyte counts over twelve-month period.

Upper-limb infusion, both unilateral and bilateral, did not demonstrate findings to the same degree. As seen from Table II, occasionally absolute lymphopenia did occur, but this was a transitory finding. The histogram (Fig. 4) of a patient who received a bilateral axillary infusion of ${ }^{131} \mathrm{I}$ Lipiodol is a fairly typical outline of the postoperative leucocyte trend in this group of patients.

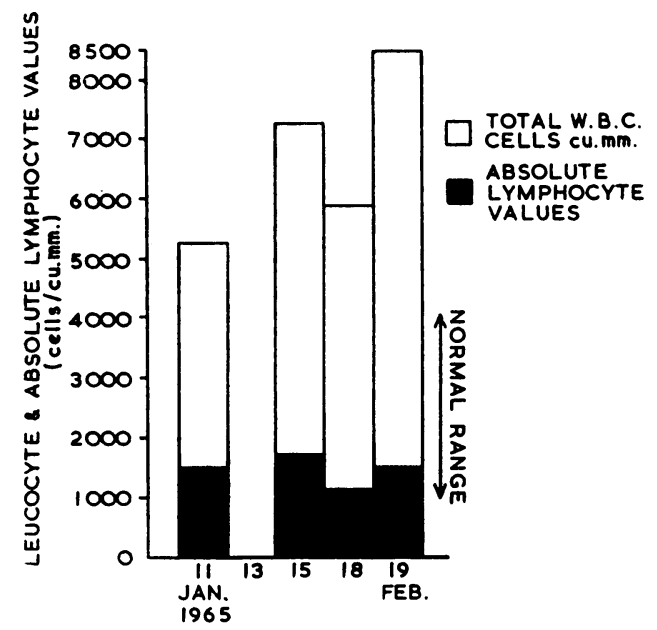

FIG. 4.-Married woman. Melanoma of interscapular area. Bilateral brachial lymphangiogram
${ }^{131}$ I Lipiodol. Dose $35 \mathrm{mCi} \times 2$. Serial W.B.C. and lymphocyte counts.

One patient in the series suffered from a melanoma of the lower back in such a situation that warranted a more extended approach. His case history is discussed in more detail, as it illustrates other important points with regard to the management of melanoma and gives data relevant to lymphopenia.

\section{Case History}

A man aged 37 , married with a family, was referred to our outpatient clinic with a view to further treatment for a melanoma of the lower part of the back.
Three months before being seen a "mole" of the back had been excised under local anaesthesia by his own doctor. This mole had been present for years but recently had been irritated by the rubbing of the camera harness that the patient had to wear during his occupation. Increase in size, both in transverse diameter and in clevation from the skin, had occurred and there had been a change in colour. Surface ulceration had also occurred, with emission of a serous discharge. After excision a biopsy report was obtained which indicated melanoma. Three weeks after the local excision small nodules developed around the scar and two months later he was referred for consideration of further treatment.

When seen in our outpatient clinic there were satellite lesions around the primary excision site to a distance of $4 \mathrm{~cm}$. radius and there were enlarged lymph nodes in the left axilla. The right axilla and both inguinal areas were adjudged clinically negative as regards lymph-node metastases. Chest $x$-ray examination showed no obvious lung deposits. The melanoma had been situated in such a position in the midline of the lumbar region that it might be expected to metastasize to the axillary and inguinal nodes of either side.

The patient was admitted for treatment as a matter of urgency. The extended therapy included, after preoperative preparation with

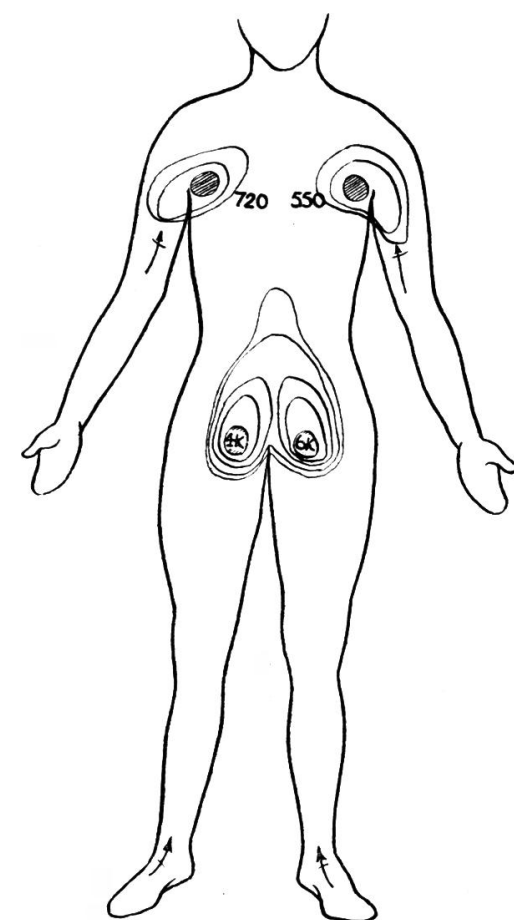

Fig. 5.-Man aged 37. Melanoma of lower back. Scanning diagram on 8 October 1965. Four-quadrant infusion of ${ }_{131}$ I Lipiodol. Bilateral brachial on 22 I Lipiodol. Bilateral brachial on 22 September. Bilateral pedal on $29 \mathrm{Sep}$ tember. Block dissection lymph nodes

Lugol's iodine by mouth to prevent thyroid uptake of ${ }^{131} I$ : (1) wide excision of primary area and application of skin graft, and bilateral intralymphatic injection to both axillae of ${ }^{131} \mathrm{I}$ Lipiodol on 22 September 1965 (Fig. 5) ; (2) bilateral intralymphatic injection of lower limbs to the ilioinguinal and para-aortic lymph nodes on 29 September (Fig. 5) ; and (3) block dissection of left axilla on 20 October (see Fig. 6). Total dosage of ${ }^{131} \mathrm{I}$ Lipiodol was:

Axillary: $35 \mathrm{mCi}$ in $2 \mathrm{ml}$. Lipiodol ${ }^{131} \mathrm{I} \times 2=70 \mathrm{mCi}{ }^{13} \mathrm{I}$

Ilioinguinal: $40 \mathrm{mCi}$ in $4 \mathrm{ml}$. Lipiodol ${ }^{131} \mathrm{I} \times 2=80 m \mathrm{Ci}^{131} \mathrm{I}$

The postoperative leucocyte and lymphocyte findings in this patient are shown in Fig. 7. A prolonged and marked drop in the absolute lymphocyte count that occurred initially was associated in the later phase with a general depression of the leucocyte count. This trend was reversing and the levels after five months were almost back to normal, though still depressed below the preoperative levels. The patient throughout has remained well and was free, clinically, of metastatic disease. In view of the late stage with involved nodes in the left axilla and the multiplicity of drainage sites his prognosis by conventional treatment standards cannot be good and fully warranted the extended therapy actually given. 


\section{Discussion}

As an almost incidental finding one of the results of endolymphatic infusion with ${ }^{131} \mathrm{I}$ Lipiodol, particularly when the ilioinguinal and para-aortic glands are treated, has been the occasional selective depression of the lymphocyte count as estimated by examination of peripheral blood samples.

This has been prolonged for up to five months in certain patients, particularly in one who was treated with bilateral lower-limb and bilateral brachial ${ }^{131}$ I Lipiodol infusions. It has had no clinical ill effects. The relevance of these findings may be in application to prolonging homograft survival, particularly in the early phase of transplantation. It is well known that the lymphocyte is concerned intimately in graft rejection,
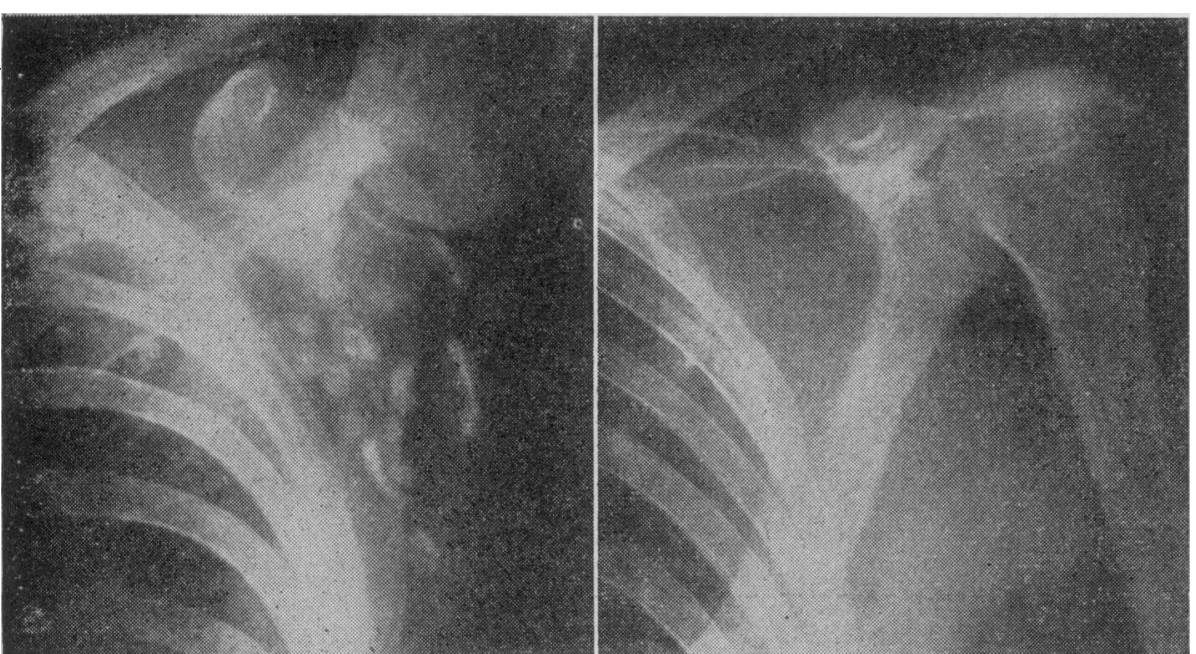

Fie. 6.- Man aged 37. Melanoma of lower back. Left, before block dissecuon. Kugnu, aster block dissection, following endolymphatic ${ }^{131} \mathrm{I}$ Lipiodol to axillae, block dissection of left axilla performed because lymph nodes were positive clinically and positive radiologically. Histology confirmed.

and current methods of producing lymphopenia with regard to delay of this phenomenon are hampered by the fact that they are not selective.

Cytotoxic agents are currently used to achieve lymphopenia during renal transplantation. Cyclophosphamide will produce a profound suppressive effect, and at Leeds a lymphocyte count of 200-300 per cu. mm. with a total count of 1,000-1,500 W.B.C./cu. mm. is aimed at (Parsons et al., 1964 ; Parsons, 1966, personal communication). Azathioprine (Imuran) is a further agent in current use, and Mowbray et al. (1965) quote total white cell counts of 1,500 .

Whole-body irradiation while decreasing the immune response produced multiple problems in patient-care (Hume, 1961), and

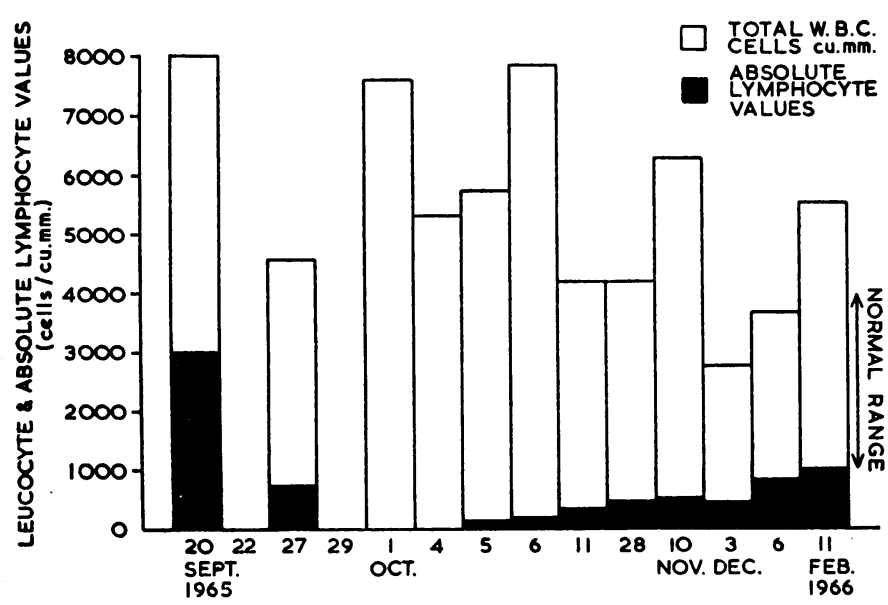

FIG. 7.- Man aged 37. Melanoma of lower back. Treated with bilateral brachial injection ${ }^{131}$ I U.F.L. on 22 September and bilateral pedal injecton ${ }^{131}$ I U.F.L. on 29 September. Serial W.B.C. and lymphocyte counts. other methods involving use of ionizing radiations have been sought. Lajtha et al. (1962) showed that extracorporeal irradiation of the blood could be carried out successfully with a cobalt $\left({ }^{60} \mathrm{Co}\right)$ source, and more recently Thomas et al. (1965) adapted the Scribner shunt for this purpose, by which blood is taken from an artery and then irradiated before return to a vein, in the treatment of leukaemia.

In experiments on animals it has been found that intralymphatic irradiation will produce a selective lymphopenia, though a generalized leucopenia may also occur. Tilak and Howard (1964) reported their experience with ${ }^{131} \mathrm{I}$ in dogs, and Wheeler et al. (1965) state than ${ }^{32} \mathrm{P}$ has also been used, and reported their own experience with ${ }^{198} \mathrm{Au}$ in dogs. They found that "intralymphatic irradiation with colloidal ${ }^{198} \mathrm{Au}$ combined with splenectomy and direct injection of isotope into mesenteric lymph nodes produces a marked selective lymphopenia in the dog which lasts for three to five weeks. The rejection of homologous renal transplants in these animals is delayed." They found that the use of azathioprine in addition " probably results in additive toxicity but also additive immunosuppression."

Our data suggest that similar lymphopenias might be produced in man by intralymphatic injections.

The selective lymphopenia in our series of patients was noted to occur particularly, as already emphasized, when the ilioinguinal and para-aortic areas were infused, and in these instances was also more prolonged.

The reason for this may not lie solely with the volume of lymphoid tissue infused, as comparison with the volume of demonstrable lymphoid tissue after bilateral brachial infusions would not be invidious. It is well known that the histological structure of lymph nodes in different areas of the body differs markedly in many respects, and it may well be that they also have different functions. It could be that the para-aortic nodes have a main function of producing lymphocytes for discharge into the general circulation via the thoracic duct ; certainly on observing the flow of contrast media through the para-aortic lymph nodes it would appear unlikely that they function purely as filtering mechanisms. Further study would be needed to elucidate this possibility. There is only a suggestion that there may be a difference in function of nodes as sources of blood lymphocytes. The lymphopenia in our patients was greatest when a greater volume of lymph tissue was injected. This applied particularly to the patient whose case is described above, in whom four-quadrant endolymphatic therapy was used.

The procedure of endolymphatic infusion is a relatively simple manœuvre and can be carried out under local anaesthesia. It may well have a place in producing selective lymphopenia in the early stage of tissue transplantation.

\section{Summary}

One of the postoperative sequelae of intralymphatic radioisotope infusions is discussed in this paper-namely, the leucocyte findings, with particular attention to selective lymphopenia.

Selective lymphopenia may be attained, particularly after lower-limb infusions, which covers normally the ilioinguinal and para-aortic glands. Even with a unilateral lower-limb infusion, with the dosage and volume of ${ }^{131} \mathrm{I}$ Lipiodol quoted in the text, an appreciable volume of lymphoid tissue is irradiated, and histological examination of lymph nodes has revealed widespread destruction. 
The relevance of these findings to problems of tissue transplantation, in particular graft rejection, is mentioned and discussed. The simplicity of the method of endolymphatic infusion in producing a lymphopenia that may last up to five months makes it a possible alternative to other methods of immunosuppression, particularly in the early phase of tissue transplantation.

We are indebted to the radioisotope and physics departments of St. Thomas's Hospital, in particular to Dr. T. M. D. Gimlette and Mr. W. F. Clapham, for advice in the preparation of this paper. Also we are grateful to Mr. D. L. Rutt for technical assistance and to Mr. T. W. Brandon, phatographic department, and Miss Dewe, medical artist, for help with the illustrations.

\section{REFERENCES}

Fortner, J. G., Booher, R. J., and Pack, G. T. (1964). Surgery, 55, 485 Hine, G. J., and Brownell, G. L. (1956). Radiation Dosimetry. New York.
Hume, D. M. (1961). The Year Book of Urology, edited by W. W. Scott, Chicago. Quoted in Lancet, 1962, 2, 385.

Jantet, G. H., Edwards, J. M., Gough, M. H., and Kinmonth, J. B. (1964). Brit. med. Э., 2, 904.

Lajtha, L G. Lewis, C. L., Oliver, R., Gunning, A. J., Sharp, A. A., and Callender, S. (1962). Lancet, 1, 353.

McGregor, D. D., and Gowans, J. L. (1963). 7. exp. Med., 117, 303.

Mowbray, J. F., Cohen, S. L., Doak, P. B., Kenyon, J. R., Owen, K., Percival, A., Porter, K. A., and Peart, W. S. (1965). Brit. med. ₹., 2, 1387 .

Parsons, F. M. (1966). Personal communication.

Raper, F. P., Fox, M., Markland, A. C., and Anderson, C. K. (1964). Transplantation, 2, 162.

Thomas, E. D., Epstein, R. B., Eschbach, J. W., Prager, D., Buckner, C. D., and Marsaglia, G. (1965). New Engl. F. Med., 273, 6.

Tilak, S. P., and Howard, J. M. (1964). Surg. Forum, 15, 160.

Wheeler, J. R., White, W. F., and Calne, R. Y. (1965). Brit. med. J., 2, 339 .

Woodruff, M. F. A. (1960). The Transplantation of Tissues and Organs, p. 95 Illinois.

\title{
Observations on the Absorption of Oral Betamethasone 17-Valerate and its Therapeutic Value in Ulcerative Colitis
}

\author{
M. FRIEDMAN,* M.D., M.R.C.P.ED. ; J. FLETCHER, † M.A., M.B., M.R.C.P. ; J. M. HINTON, † M.A., B.M., M.R.C.P. \\ J. E. LENNARD-JONES, †§ M.A., M.D., M.R.C.P. ; J. J. MISIEWICZ,†§ M.B., B.SC. \\ J. A. PARRISH, $+\|$ M.D., M.R.C.P.
}

Brit. med. F., 1967, 1, 335-337

Oral betamethasone 17-valerate (Betnovate) has been put forward as an effective treatment for ulcerative colitis which has the great advantage that it causes neither adrenal suppression nor the usual side-effects of steroid therapy (Morton Gill et al., 1965). A steroid which is not absorbed after oral administration but which is topically active in the large intestine would be a major advance in the treatment of colitis. We have therefore studied the absorption of betamethasone 17-valerate in normal subjects by measuring its effect on adrenal function. In patients with ulcerative colitis we have studied its use as a treatment and correlated the clinical results with studies of adrenal function.

\section{Methods}

Heparinized blood samples were collected between 9 and 10 a.m. The plasma was separated within 30 minutes of venepuncture and stored at $-4^{\circ}$ C. until the estimations were performed. The plasma cortisol was measured as free plasma total 11-hydroxycorticosteroids by a modification of the fluorometric method of Mattingly (1962) (Black and Friedman, 1965). With this method the normal range of plasma cortisol level at 9 a.m. is $8-28 \mu \mathrm{g} . / 100 \mathrm{ml}$.

\section{Studies in Normal Subjects}

Studies were carried out on seven normal subjects who were without any previous gastrointestinal symptoms. They were members of the hospital staff, three men and four women, aged 24 to 39 years.

\footnotetext{
- Paediatric Departments, University College Hospital and the Whittington Hospital, London. † St. Mark's Hospital, London.

$\$$ In receipt of a grant from the Medical Research Council.

Member of the Medical Research Council Gastroenterology Research Unit, Central Middlesex Hospital, London N.W.10.

H Physician, Mayday Hospital, Croydon, Surrey.
}

Five studies were performed (Fig. 1). In the first two each subject took by mouth in divided six-hourly doses for 48 periods (A) $2 \mathrm{mg}$. daily of dexamethasone and (B) $2 \mathrm{mg}$. daily of betamethasone free alcohol. In a third study (C) each subject took 2,4 , and $8 \mathrm{mg}$. daily of betamethasone 17-valerate in divided six-hourly doses for consecutive 48-hour periods. In a fourth study (D) the two subjects in whom adrenal suppression did not occur on $8 \mathrm{mg}$. daily of betamethasone 17-valerate in the third study $(\mathrm{C})$ were given $12 \mathrm{mg}$. daily in divided doses six-hourly for 48 hours. In a fifth study (E) three subjects were given $8 \mathrm{mg}$. daily of betamethasone 17-valerate in divided doses six-hourly for $\mathbf{4 8}$ hours. The studies were not carried out in any fixed order and at least a week was allowed to elapse between each one. The plasma cortisol was measured before and after each 48-hour period, the last blood specimen being taken within three hours of the final dose.

\section{Studies in Patients with Ulcerative Colitis}

Twenty-seven outpatients with ulcerative colitis were treated. Preliminary clinical observations were made in 17 patients who were given 4 or $8 \mathrm{mg}$. of betamethasone 17 -valerate daily by mouth in divided doses. Ten further patients were treated with $8 \mathrm{mg}$. daily for two to four weeks. In these ten patients the clinical results were correlated with plasma cortisol levels measured before treatment, and at two and/or four weeks. The patients were asked to take the tablets four times daily and to ensure that one was taken on the morning of the visit to the clinic. At each attendance they were asked whether any tablets had been missed. No direct inquiry was made about sideeffects. The results of treatment were assessed symptomatically and sigmoidoscopically, as described in previous trials (Baron et al., 1962b). A remission is defined as complete freedom from symptoms with a non-haemorrhagic non-friable mucosa on sigmoidoscopy. 